\title{
Angiotensin-converting enzyme 2 alleviates pulmonary artery hypertension through inhibition of focal adhesion kinase expression
}

\author{
RUI WANG ${ }^{1,2}$, JINGJING XU $^{2}$, JINBO WU $^{2}$, SHUNHENG GAO ${ }^{2}$ and ZHIPING WANG ${ }^{1,2}$ \\ ${ }^{1}$ Department of Anesthesiology, Affiliated Hospital of Xuzhou Medical University, Xuzhou, Jiangsu 221006; \\ ${ }^{2}$ Department of Anesthesiology, Wuxi People's Hospital Affiliated to Nanjing Medical University, \\ Wuxi, Jiangsu 214023, P.R. China
}

Received February 28, 2020; Accepted July 15, 2021

DOI: $10.3892 /$ etm.2021.10599

\begin{abstract}
Focal adhesion kinase (FAK) is an important therapeutic target in pulmonary artery hypertension (PAH); however, the mechanism of its activation remains unknown. The present study aimed to investigate whether angiotensin-converting enzyme 2 (ACE2) could regulate FAK and alleviate PAH in a rat model of $\mathrm{PAH}$ established with a single administration of monocrotaline followed by continuous hypoxia treatment. In the current study, right ventricular pressure, body weight and the right ventricular hypertrophy index were measured, and hematoxylin-eosin staining was performed on lung tissues to determine whether the modeling was successful. Changes in the serum levels of FAK were measured using an ELISA kit to evaluate the association between ACE2 and FAK. The mRNA expression levels of ACE2, FAK, caspase-3 and survivin were determined using reverse transcription-quantitative PCR (RT-qPCR). The protein expression levels of ACE2, phosphorylated FAK/FAK, cleaved caspase-3/pro-caspase-3 and survivin were determined via western blotting. Immunohistochemistry was applied to detect the expression of FAK around the pulmonary arterioles. Apoptosis of smooth muscle cells around pulmonary arterioles was observed by TUNEL staining. After treatment with the ACE2 activator DIZE or inhibitor DX-600, the results demonstrated that ACE2 reduced $\mathrm{PAH}$-induced changes in arteriole morphology compared with the control. It also inhibited FAK expression in serum. WB and RT-qPCR results suggested that ACE2 inhibited the expression of FAK and pathway-related proteins, and promoted caspase-3 expression. Additionally, ACE2 reduced FAK expression around the pulmonary arterioles and
\end{abstract}

Correspondence to: Dr Zhiping Wang, Department of Anesthesiology, Affiliated Hospital of Xuzhou Medical University, 99 Huaihai West Road, Xuzhou, Jiangsu 221006, P.R. China E-mail: zhpsqxt@126.com

Key words: pulmonary artery hypertension, angiotensin-converting enzyme 2, apoptosis, focal adhesion kinase, angiotensin II promoted smooth muscle cell apoptosis. The results indicated that ACE2 activation inhibited FAK expression, leading to alleviation of the symptoms of $\mathrm{PAH}$.

\section{Introduction}

Pulmonary artery hypertension (PAH) is a persistent and fatal disease that is associated with a variety of factors, including heredity, prolonged hypoxia and inflammation (1). PAH is characterized by a continuous increase in pulmonary arterial pressure and right-sided heart failure (1). As a bridge to chronic pulmonary heart disease, hypoxic pulmonary hypertension is also associated with high rates of mortality in elderly individuals in China, which begins with persistent hypoxia (2). A previous study on the mortality of PAH in Australia showed that patients with pulmonary artery pressure $>60 \mathrm{mmHg}$ had a mortality rate of $>40 \%$ within 1 year and a mortality rate of $\sim 80 \%$ within 5 years (3). The main histological characteristics of PAH include the excessive proliferation of pulmonary artery smooth muscle cells (PASMCs) and the accumulation of PASMCs in the distal pulmonary arterioles, leading to increased myogenic arteries, hence reducing the compliance of pulmonary arterioles (2). Pulmonary vascular remodeling (PVR), a major cause of PAH irreversibility, occurs due to the proliferation of PASMCs (3). The PAH process is accompanied by the activation of mast cells (4). Mast cells can synthesize and secrete IL-6 (5). IL-6 then stimulates B cells to secrete autoantibodies (6). The general abundance of autoantibodies in the circulating blood of PAH rats, coupled with the disability in targeting the immune intervention to inhibit cell proliferation of PASMC, suggest that autoantibodies are an important cause of PASMC apoptosis resistance (7). A decreased expression of p62 and markedly increased ratio of LC3-II/LC3-I suggest that autophagy is activated in the lung tissues of rats during PAH (8). The activation of autophagy is involved in hypoxia-induced PASMC proliferation and migration, which is restored to baseline levels in hypoxia-exposed PASMCs treated with the autophagy inhibitor 3-MA $(9,10)$. At present, no specific therapeutic agents that are effective for pulmonary hypertension exist (11). Only symptom-alleviation treatments, including endothelin receptor antagonists and 
phosphodiesterase inhibitors, in addition to strategies to promote arterial vasodilation, such as prostanoids and calcium channel blockers, can be used for clinical treatment (11). However, these treatments aforementioned can only partially effective in improving the symptoms and prolong life expectancy (12). Therefore, the present study aimed to develop more effective PAH treatment strategies and explore the mechanism underlying the pathological accumulation of PASMCs.

Similarities between the pathophysiology of malignancies and PAH have been found (13). In particular, focal adhesion kinase (FAK) and survivin were found to be associated with PAH (14). FAK was originally identified to be an important therapeutic target protein for diseases involving abnormal cell proliferation, including liver fibrosis (15) and PAH (16). Operating downstream protein of FAK (17), survivin is a member of the inhibitor of apoptosis protein family and promotes the proliferation of PASMCs through inhibition of the caspase-3 pathway $(18,19)$. However, the underlying mechanism has not been fully elucidated. Previous studies have suggested that angiotensin (Ang) II can increase FAK expression, which is known to be involved in the development of tumors and is also an important factor in the development of normal cells such as fibroblasts and epithelial cells (20). Ang II-activated FAK could lead to liver fibrosis (21), macrophage accumulation during atherosclerosis $(22,23)$, proteinuric kidney disease (24) and the growth and extension of climbing fiber innervation to some extent $(25,26)$. However, to the best of our knowledge, whether Ang II can also increase FAK expression in PAH has not been previously reported.

$\mathrm{PAH}$ is often accompanied by the activation of the renin angiotensin system (RAS) and Ang II (27), leading to the activation of hypoxia-inducible factor 1 (HIF-1). HIF-1-deficient cells frequently exhibit increased apoptosis (28). Unfortunately, the activation of HIF-1 is followed by the activation of Ang II, which in turn activates RAS, resulting in a vicious circle (29). Within the RAS, ang-converting enzyme (ACE) converts ang I into vasoconstrictor Ang II, which regulates salt/water homeostasis and vasoconstriction, modulates blood pressure and is also implicated in inflammation, endothelial dysfunction and oxidative stress (30). Therefore, ACE inhibitors (ACEis) have been widely used to treat diseases such as hypertension involving the overproduction of Ang II; however, ACEi may cause side effects such as hypotension (24). The majority of patients with PAH exhibit reductions in cardiac output, which may cause hypotension and insufficient organ perfusion (3). Therefore, ACEis treatment may increase the risk of hypotension and insufficient organ perfusion (31). ACE2 was investigated in the present study as it decomposes Ang II into Ang (1-7), which reduces the Ang II concentration, allowing the RAS to regulate blood pressure, and water and electrolyte balance (32).

In the present study, it was hypothesized that an association exists between Ang II and FAK during the occurrence of PAH. To test this hypothesis, a rat model of PAH was established with a single administration of monocrotaline and continuous hypoxia treatment before the application of ACE2 activators or inhibitors. The severity of PAH in rats was then assessed, following which changes in the serum levels of FAK in plasma, the mRNA expression of ACE2, FAK, caspase-3 and survivin, the protein expression of ACE2, pFAK/FAK, cleaved caspase-3/pro-caspase-3 and survivin and the expression of FAK around pulmonary arterioles, in addition to apoptosis, was measured.

\section{Materials and methods}

Animals and experimental intervention. A total of 36 male Sprague-Dawley rats (weight, 160-180 g; age, 8 weeks) were purchased from Changzhou Cavens Laboratory Animal Co., Ltd. (http://www.cavens.com.cn/). All rats had free access to food and water and were housed at $22 \pm 1^{\circ} \mathrm{C}$ with $50 \pm 10 \%$ relative humidity at a $12-\mathrm{h}$ light/dark cycle. The animal care was in accordance with the National Institutes of Health Guide for the Care and Use of Laboratory Animals (33), and the study was approved by the Animal Use and Protection Committee of Wuxi People's Hospital (Wuxi, China). The rats were randomized into six groups (n=6/group): i) Normal (N) group, subcutaneous injection $(\mathrm{iH})$ and intraperitoneal injection (ip) with normal saline (NS); ii) diminazene aceturate (DIZE) group, treatment with iH administration of $15 \mathrm{mg} / \mathrm{kg} /$ day DIZE (Sigma-Aldrich; Merck KGaA), a specific ACE2 activator (34), with an equivalent volume of NS ip; iii) DX-600 group, treatment with $0.1 \mu \mathrm{mol} / \mathrm{kg} /$ day ACE2 inhibitor DX-600 (Cayman Chemical Company) $(35,36)$ ip and an equivalent volume of $\mathrm{NS} \mathrm{iH}$; iv) $\mathrm{PAH}$ group, continuous hypoxia with NS ip and $\mathrm{iH}$; v) $\mathrm{PAH}+$ DIZE group, continuous hypoxia with $15 \mathrm{mg} / \mathrm{kg} /$ day DIZE iH and NS ip; and vi) PAH + DX-600 group, continuous hypoxia with $0.1 \mu \mathrm{mol} / \mathrm{kg} /$ day DX-600 ip and NS iH. The rats were treated for 21 days.

The PAH rat model was established with a single $\mathrm{iH}$ administration of monocrotaline (MCT; cat. no. IC0930; Beijing Solarbio Science \& Technology, Co., Ltd.) and continuous hypoxia treatment (37). The rats were then treated with saline, DIZE or DX-600 before beign returned into the hypoxic chamber. The daily injection time was from 8:00 to 8:30 am in the morning, during which time the rats were in a normoxic room. During the 28 days of hypoxia, drug administration was only performed for the first 21 days i.e on day 21 of modeling, the rats were injected with saline, DIZE or DX-600 for the final time. No drugs were injected during the last 7 days of modeling. The successful establishment of modeling was determined by measuring rat weight, right ventricular systolic pressure (RVSP), right ventricular hypertrophy index (RVHI) and observing pathological changes (38). The rats in the PAH group were fed in a special KY-2F hypoxic tank (Fig. 1; Jiande Meicheng Analysis Instrument Factory), whilst rats in the normoxic group were fed in a normal oxygen environment. The KY-2F oxygen controller monitored the oxygen concentration in real time.

The PAH groups adapted to a $12 \%$ oxygen concentration for 2 days, and then a continued low flow of nitrogen was introduced into the tank to control the oxygen concentration to between $8-9 \%$. On the first day of modeling, MCT $60 \mathrm{mg} / \mathrm{kg}$ iH was administered to the three PAH model groups, while an equivalent volume of NS iH was administered to the three groups under normal oxygen conditions. During the modeling period, food and water were changed for each group, the rats were weighed, drugs were administered, and the tank was ventilated for $1 \mathrm{~h}$ daily. After $1 \mathrm{~h}$, the 


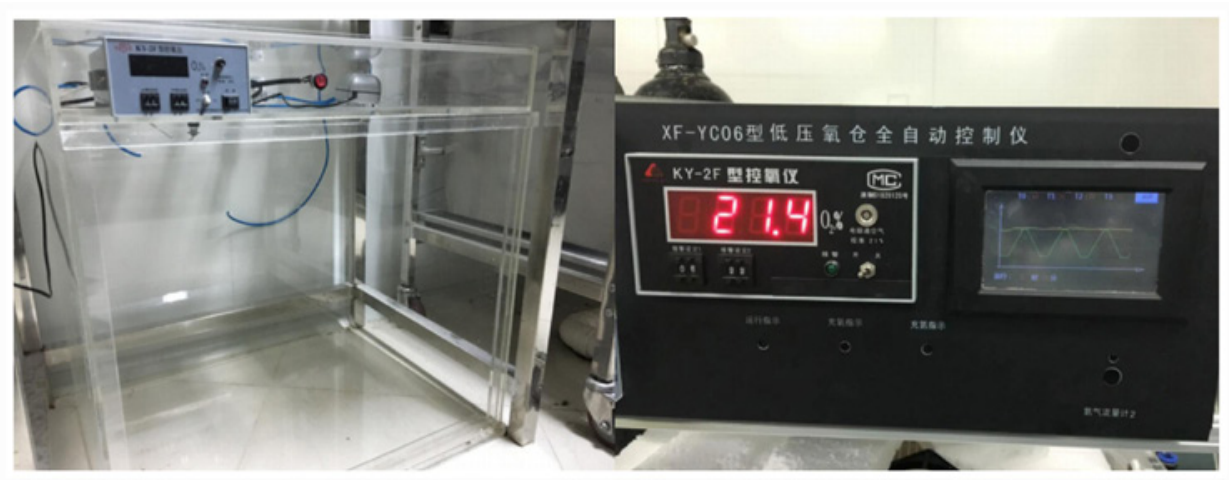

Figure 1. Hypoxia tank and oxygen controller. The hypoxic tank was prepared from an acrylic sheet. The tank could be opened from the outside. It carried two channels to transport nitrogen and oxygen separately. The KY-2F oxygen controller monitored the oxygen concentration in real time.

rats in the three PAH model groups were placed back into the hypoxic tank, and the tank was filled with nitrogen. The treatment lasted for 4 weeks.

Treatment of rats after modeling. The rats were anesthetized with pentobarbital sodium $(40 \mathrm{mg} / \mathrm{kg})$ intraperitoneally and placed flat on the experiment table. The hair on the chest and neck was removed with a shaver, the skin was cut through a median and vertical incision and the thyroid was removed. Cotton threads were passed through the back of the trachea to expose it fully. Tracheotomy at the middle of the trachea and tracheal intubation ensured the ventilation of the rats. After connecting the tracheal tube to the Inspira ventilator (https://www.dlnaturegene.net/pdlistone/products/11681692.html), the parameters were set according to the weight of the rats.

Before measuring the RVSP, necessary preparations were conducted. A sensor was connected to a PowerLab system (AD Instruments) and zeroed. Then, a plastic catheter with a diameter of $1 \mathrm{~mm}$ was prepared. It was rinsed, and heparin sodium was injected with a sensor tubing. The internal jugular vein was located from the right side of the trachea and the catheter placed into the vein under B-ultrasound (Mindray Medical International, Co., Ltd.) to ensure its placement in the right ventricle. Subsequently, the RVSP was recorded. After recording the data, the catheter was removed and the wound was clamped with forceps to prevent bleeding.

After cutting the sternum from the middle, the rats were exsanguinated, and $1.5 \mathrm{ml}$ blood was collected from the right ventricle and placed in a tube to determine the serum level of FAK.

The rat heart and lung tissues were washed with phosphate-buffered saline (PBS), and the excess tissues and trachea were cut off. The pulmonary artery was separated on ice from the secondary branch, and the water was blotted with an absorbent paper. The right apex of the lung was fixed with $4 \%$ formaldehyde for $24 \mathrm{~h}$ at room temperature and used for histopathological examination. The remaining lung was cut into pieces and stored in liquid nitrogen.

The right and left atrial appendages of the heart were cut off, and the heart was perfused with PBS from the left atrial appendage. When the right atrial appendage effluent was transparent, the right ventricle, the left ventricle and the ventricular septum were separated. An absorbent paper was used to dry the three parts, which were then weighed. RVHI was calculated using the following formula: RVHI=right ventricle/(left ventricle + ventricular septum).

Quantification of FAK expression. Blood $(1.5 \mathrm{ml})$ was taken from the right ventricle and placed in a tube. The blood was left to coagulate at room temperature for $20 \mathrm{~min}$ and then centrifuged for $20 \mathrm{~min}\left(1,000 \mathrm{x} \mathrm{g} ; 4{ }^{\circ} \mathrm{C}\right)$. The supernatant was carefully collected and stored at $-80^{\circ} \mathrm{C}$. FAK expression levels in the serum were determined using an ELISA kit (cat. no. SBJ-R1023-96T; Nanjing SenBeiJia Biological Technology, Co., Ltd.; https://www.biomart.cn/infosupply/99217435.html) according to the manufacturer's instructions. The absorbance values were measured at $450 \mathrm{~nm}$ using a spectrophotometer (Thermo Fisher Scientific, Inc.).

Reverse transcription-quantitative (RT-q)PCR. The mRNA expression levels of related factors were determined to evaluate the effect of DIZE on PAH. The total RNA was extracted from lung tissue using TRIzol ${ }^{\circledR}$ (Thermo Fisher Scientific, Inc.). The RNA yield and purity were determined with a NanoDrop 2000/2000c Spectrophotometer (NanoDrop Technologies; Thermo Fisher Scientific, Inc.) using the ratio of absorbance at 260 and $280 \mathrm{~nm}$. Reverse transcription was performed with a PrimeScript ${ }^{\mathrm{TM}} \mathrm{RT}$ reagent kit (Takara Bio, Inc.) using the following protocol: $30^{\circ} \mathrm{C}$ for $10 \mathrm{~min}, 42^{\circ} \mathrm{C}$ for $30 \mathrm{~min}$ and $99^{\circ} \mathrm{C}$ for $5 \mathrm{~min}$ followed by $5^{\circ} \mathrm{C}$ for $5 \mathrm{~min}$. qPCR was then conducted with a QuantiNova STBR Green PCR kit (Qiagen $\mathrm{GmbH})$. Thermocycling conditions were as follows: $95^{\circ} \mathrm{C}$ for $2 \mathrm{~min}$, followed by 45 cycles of $94^{\circ} \mathrm{C}$ for $15 \mathrm{sec}, 55^{\circ} \mathrm{C}$ for $15 \mathrm{sec}$ and $68^{\circ} \mathrm{C}$ for $30 \mathrm{sec}$ and final elongation at $72^{\circ} \mathrm{C}$ for $5 \mathrm{~min}$. All the primers in this study were synthesized by Sangon Biotech Co., Ltd. Primer sequences were as follows: TATA binding protein (TBP) forward, 5'-CCCACCAGCAGT TCAGTAGC-3' and reverse, 5'-GAATTCTGGGTTTGATCA TTCTG-3'; FAK forward, 5'-CACCTGATGGAAGAGCGG CTAATC-3' and reverse, 5'-GGATCGGTCAAGGTTGGC AGTG-3'; caspase-3 forward, 5'-GTACAGAGCTGGACT GCGGTATTG-3' and reverse, 5'-AGTCGGCCTCCACTG GTATCTTC-3'; survivin forward, 5'-TGGCGGAGGCTG GCTTCATC-3' and reverse, 5'-CGGTCAGTTCTTCCACCT GCTTC-3'; and ACE2 forward, 5'-AAGCCACCTTACGAG CCTCCTG-3' and reverse, 5'-AACAATGCCAACCACTAC CGTTCC-3'. The $2^{-\triangle \triangle C q}$ method (with TBP as an internal reference primer) was used to quantify mRNA expression (39). 

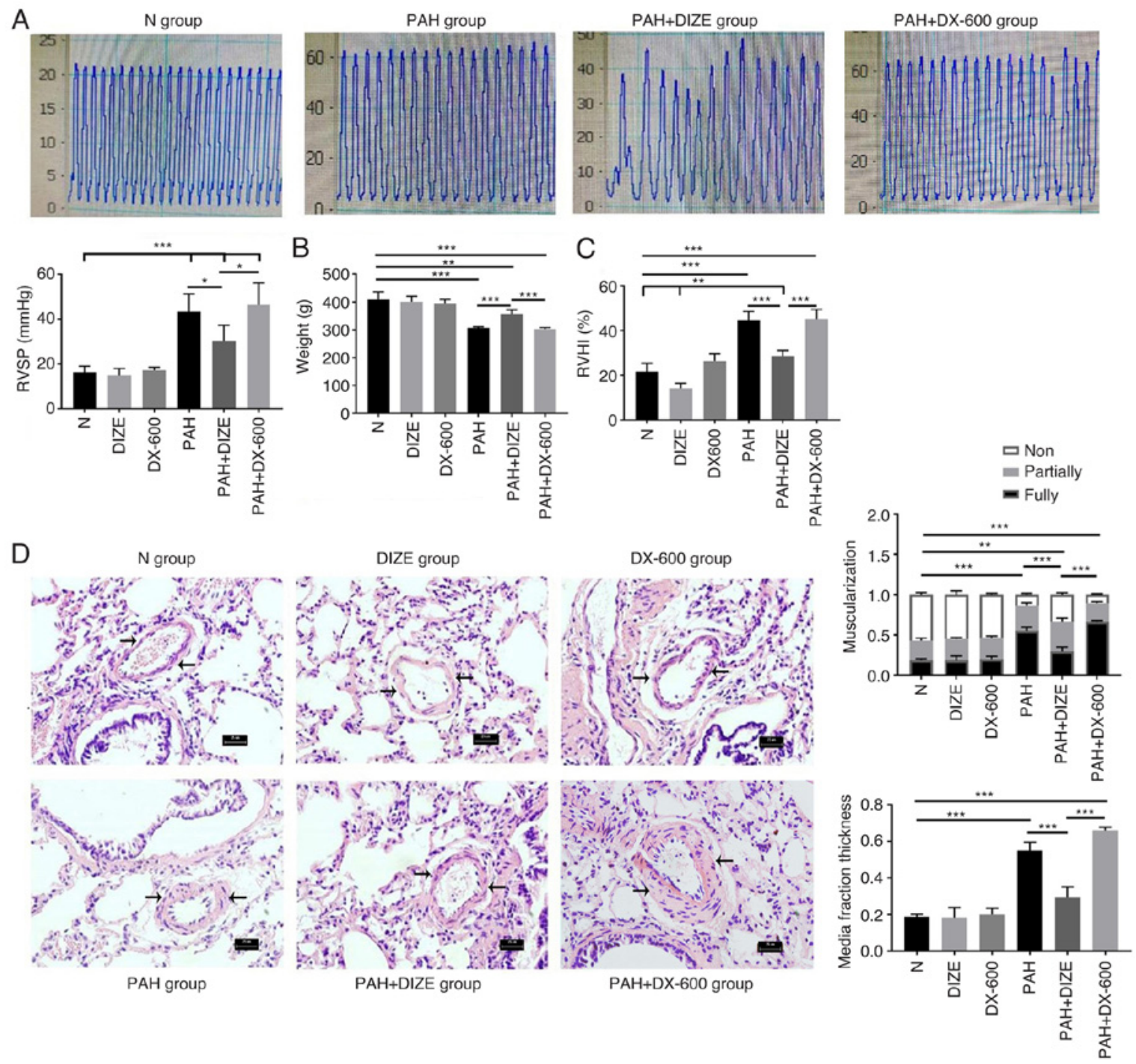

Figure 2. Effect of DIZE on normal rats and in a hypoxia-induced PAH rat model. Rats were randomly divided into N, DIZE, DX-600, PAH, PAH + DIZE and PAH + DX-600 groups (n=6/group). The DIZE, PAH + DIZE, DX-600 and PAH + DX-600 groups were injected with DIZE or DX-600 for the first 3 weeks of hypoxia. (A) Representative trace of RVSP in the N, PAH, PAH + DIZE and PAH+DX-600 groups, and quantification of RVSP in all groups. (B) Weight, (C) RVHI and (D) morphology of the pulmonary arterioles in the N, DIZE, DX-600, PAH, PAH + DIZE and PAH + DX-600 groups (magnification, $x 400$ ). In addition, percentage of muscularization and assessment of medial thickness in all groups were conducted. ${ }^{*} \mathrm{P}<0.05,{ }^{* *} \mathrm{P}<0.01,{ }^{* * *} \mathrm{P}<0.001$. RVSP, right ventricular systolic pressure; RVHI, right ventricular hypertrophy index; N, normoxic; DIZE, diminazene aceturate; PAH, pulmonary artery hypertension.

Western blot analysis. The lung tissues were homogenized using RIPA buffer (cat. no. P0013C; Beyotime Institute of Biotechnology) and protease inhibitor cocktail (cat. no. HY-K0010; MedChem Express). The protein concentrations were determined using a bicinchoninic acid assay kit (cat. no. P0012S; Beyotime Institute of Biotechnology). The samples were centrifuged at $3,000 \mathrm{x}$ g at $4^{\circ} \mathrm{C}$ for $30 \mathrm{~min}$ to obtain the supernatants. Sample volumes containing $60 \mu \mathrm{g}$ protein were separated via $12 \%$ SDS-PAGE and transferred onto PVDF membranes (Biosharp Life Sciences). After blocking nonspecific binding with $5 \%$ non-fat milk at $25^{\circ} \mathrm{C}$ for $1 \mathrm{~h}$, the membranes were incubated with the following primary antibodies at $4^{\circ} \mathrm{C}$ overnight: Mouse anti-b-tubulin (1:1,000; cat. no. 2146; Cell Signaling Technology, Inc.); rabbit anti-ACE2 (1:1,000; cat. no. ab108252; Abcam), rabbit anti-FAK (1:1,000; cat. no. ab40794; Abcam), rabbit anti-phosphorylated (p)-FAK (Y397; 1:1,000; cat. no. ab81298; Abcam), rabbit anti-caspase-3 (pro-caspase 3, $34 \mathrm{kDa}$; cleaved caspase 3, $17 \mathrm{kDa}$; 1:500; cat. no. ab13847; Abcam) and rabbit anti-survivin (1:500; cat. no. ab134170; Abcam). After washing with Tris Buffered Saline with 0.1\% Tween-20 (TBST, cat. no. 9997s; Cell Signaling Technology, Inc.), the membranes were incubated with diluted HRP-conjugated goat anti-mouse IgG (1:1,000; cat. no. 91196s; Cell Signaling Technology, Inc.) or goat anti-rabbit IgG (1:3,000, cat. no. 7074s; Cell Signaling Technology, Inc.) for $2 \mathrm{~h}$ at $25^{\circ} \mathrm{C}$ and developed with enhanced chemiluminescence reagents (EMD Millipore). The optical densities were analyzed using Image Lab (version 4.0; Bio-Rad Laboratories, Inc.). $\beta$-tubulin was used as a loading control.

Hematoxylin-eosin (HE) staining. The right pulmonary apex tissue was fixed with $4 \%$ paraformaldehyde for $24 \mathrm{~h}$ at $25^{\circ} \mathrm{C}$, dehydrated using an ascending ethanol gradient, embedded in paraffin wax, embedded and cut into sections with a thickness of $4 \mu \mathrm{m}$. The sections were dewaxed using xylene, rehydrated with a descending graded ethanol series, stained with H\&E 


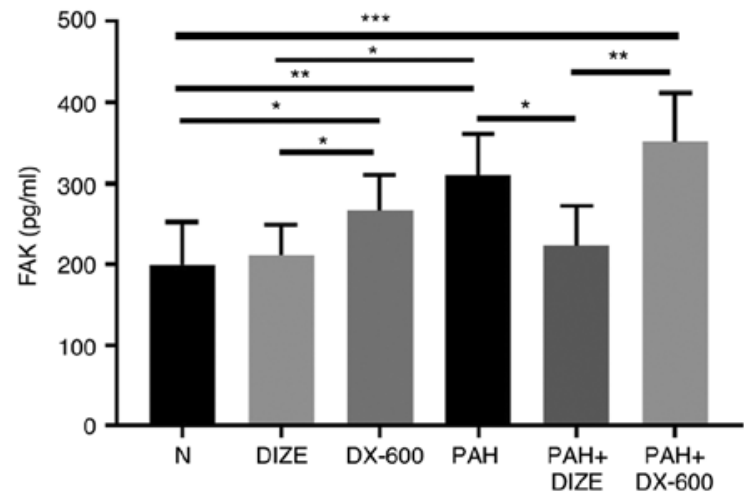

Figure 3. Effect of DIZE on FAK expression in normal rats and a hypoxia-induced PAH rat model. Rats were randomly divided into the $\mathrm{N}$, DIZE, DX-600, PAH, PAH + DIZE and PAH + DX-600 groups (n=6/group). The DIZE, PAH + DIZE, DX-600 and PAH + DX-600 groups were injected with DIZE or DX-600 for the first 3 weeks of hypoxia. ${ }^{*} \mathrm{P}<0.05,{ }^{* *} \mathrm{P}<0.01$, ${ }^{* * *} \mathrm{P}<0.001$. FAK, focal adhesion kinase; $\mathrm{N}$, normoxic; DIZE, diminazene aceturate; PAH, pulmonary artery hypertension.

(0.5\% hematoxylin for $5 \mathrm{~min}$ followed by $0.5 \%$ eosin for $1 \mathrm{~min}$, both at $25^{\circ} \mathrm{C}$ ), hydrated with a graded alcohol series and dehydrated with xylene. The images were acquired using an inverted light microscope (magnification, x400; model, Leica DMi8; Leica Microsystems GmbH) under white light. Pulmonary arterioles with a diameter of $\sim 50 \mu \mathrm{m}$ were observed using Image-Pro Plus (version 6.0; Media Cybernetics, Inc.).

In total, 20-40 small pulmonary arteries with a diameter of $\sim 50 \mu \mathrm{m}$, were taken from each group. According to the morphology of the arteries, they were divided into non-muscularized arteries (internal acinar arteries without muscularization of the vessel wall), partially muscularized arteries (the muscularization of the vessel wall $\leq 75 \%$ of the vascular radius) and fully-muscularized arteries (the muscularization of the vessel wall $>75 \%$ of the vascular radius) (40). The extent of muscularization of each group was calculated according to the ratio. In addition, 25 pulmonary arterioles with a diameter of $\sim 50 \mu \mathrm{m}$ were selected in each group, before Image-Pro Plus (version 6.0; Media Cybernetics, Inc.) was used to measure the inner and outer diameters of the lumen. From these, the ratio of the pulmonary artery media thickness to the outer diameter was calculated to deduce the media fraction thickness of each group.

TUNEL staining. The paraffin-embedded sections, prepared using protocols aforementioned, were incubated at $60^{\circ} \mathrm{C}$ for $1 \mathrm{~h}$ and stained using a One-Step TUNEL Apoptosis Assay Kit (cat. no. KGA7073; Nanjing KeyGen Biotech Co., Ltd.) according to the manufacturer's protocol. First, tissue slides were treated with proteinase $\mathrm{K}(100 \mu \mathrm{l})$ for $30 \mathrm{~min}$ at $37^{\circ} \mathrm{C}$. After rinsing with PBS, the tissue slides were treated with a TdT enzyme reaction solution ( $50 \mu \mathrm{l}$; a mixture of $45 \mu \mathrm{l}$ equilibration buffer, $1 \mu 1$ biotin-11-dUTP and $4 \mu 1$ TdT enzyme) for $60 \mathrm{~min}$ at $37^{\circ} \mathrm{C}$. The samples were incubated in a humidity chamber (plastic box with PBS). Sections were incubated with streptavidin-fluorescein (5 $\mu \mathrm{l})$ and labeling buffer $(45 \mu \mathrm{l})$ for $30 \mathrm{~min}$ at $37^{\circ} \mathrm{C}$. Sections were then incubated with $5 \mu \mathrm{g} / \mathrm{ml}$ DAPI for $10 \mathrm{~min}$ at $25^{\circ} \mathrm{C}$. After rinsing with PBS, the sections were treated with glycerin PBS seal tablets (glycerin: $P B S=6: 4$; cat. no. ST1353; Beyotime Institute of Biotechnology). The apoptotic cells showing green fluorescence were observed under an inverted fluorescence microscope (magnification, $\mathrm{x} 400$ ) and photographed using Image-Pro Plus (version 6.0; Media Cybernetics, Inc.). In total, five random fields were selected for each sample, which were analyzed using ImageJ software v1.0 (National Institutes of Health). The positive points of DAPI were the total number of cells, whilst the positive points of FITC were the apoptotic positive cells. Finally, the proportion of apoptotic cells calculated using the formula FITC/DAPI x $100 \%$.

Immunohistochemistry (IHC) staining. IHC staining was conducted to evaluate the immunoreactivity of FAK. The paraffin-embedded sections, prepared using protocols aforementioned, were dewaxed with xylene, hydrated with a descending graded ethanol series. The tissue sections were then blocked using an enhanced endogenous peroxidase blocking buffer (cat. no. P0100B; Beyotime Institute of Biotechnology) at $25^{\circ} \mathrm{C}$ for $10 \mathrm{~min}$. After washing twice with $\mathrm{PBS}$, the sections were heated to $96-98^{\circ} \mathrm{C}$ for 15 min inducing epitope retrieval with a citrate antigen retrieval solution (cat. no. P0081; Beyotime Institute of Biotechnology). The sections were rinsed with PBS and then blocked with $10 \%$ goat serum (cat. no. C0265; Beyotime Institute of Biotechnology) at $37^{\circ} \mathrm{C}$ for $30 \mathrm{~min}$. The sections were then probed with rabbit anti-FAK (1:250; cat. no. ab40794; Abcam) at $4^{\circ} \mathrm{C}$ for $12 \mathrm{~h}$ followed by HRP-conjugated goat anti-rabbit secondary antibodies at $37^{\circ} \mathrm{C}$ for $1 \mathrm{~h}$ (1:5,000; cat. no. ab205718; Abcam). Fixed tissues were stained with DAB (cat. no. P0203; Beyotime Institute of Biotechnology) at $25^{\circ} \mathrm{C}$ for $30 \mathrm{~min}$. After washing thoroughly with distilled water, the sections were stained with hematoxylin at $25^{\circ} \mathrm{C}$ for $10 \mathrm{~min}$ and then differentiated with an acidic ethanol differentiation solution at $25^{\circ} \mathrm{C}$ for $5 \mathrm{sec}$ (cat. no. C0107; Beijing Solarbio Science \& Technology, Co., Ltd.). After further rinsing with distilled water, the sections were hydrated with a graded alcohol series and dehydrated with xylene. They were observed under x400 magnification with an inverted light microscope under white light and the images were collected using Image-Pro Plus (version 6.0; Media Cybernetics, Inc.). FAK expression was indicated as yellowish-brown particles.

Statistical analysis. The data are presented as the mean \pm standard error of mean. Statistical analysis was performed using SPSS version 22.0 (IBM Corp.). Comparison among groups was performed by one-way analysis of variance. Post hoc analyses were performed using Tukey's multiple comparisons test. $\mathrm{P}<0.05$ was considered to indicate a statistically significant difference.

\section{Results}

ACE2 alleviates PAH-induced morphological changes. The hypoxic treatment lasted for 4 weeks. The rats in each group were weighed and treated according to the procedure. The preoperative body weight of rats was significantly higher in the $\mathrm{N}$ group compared with that in the PAH group (Fig. 2B). By contrast, the RVSP and RVHI values were lower in the $\mathrm{N}$ group compared with in the PAH group (Fig. 2A and C). The 

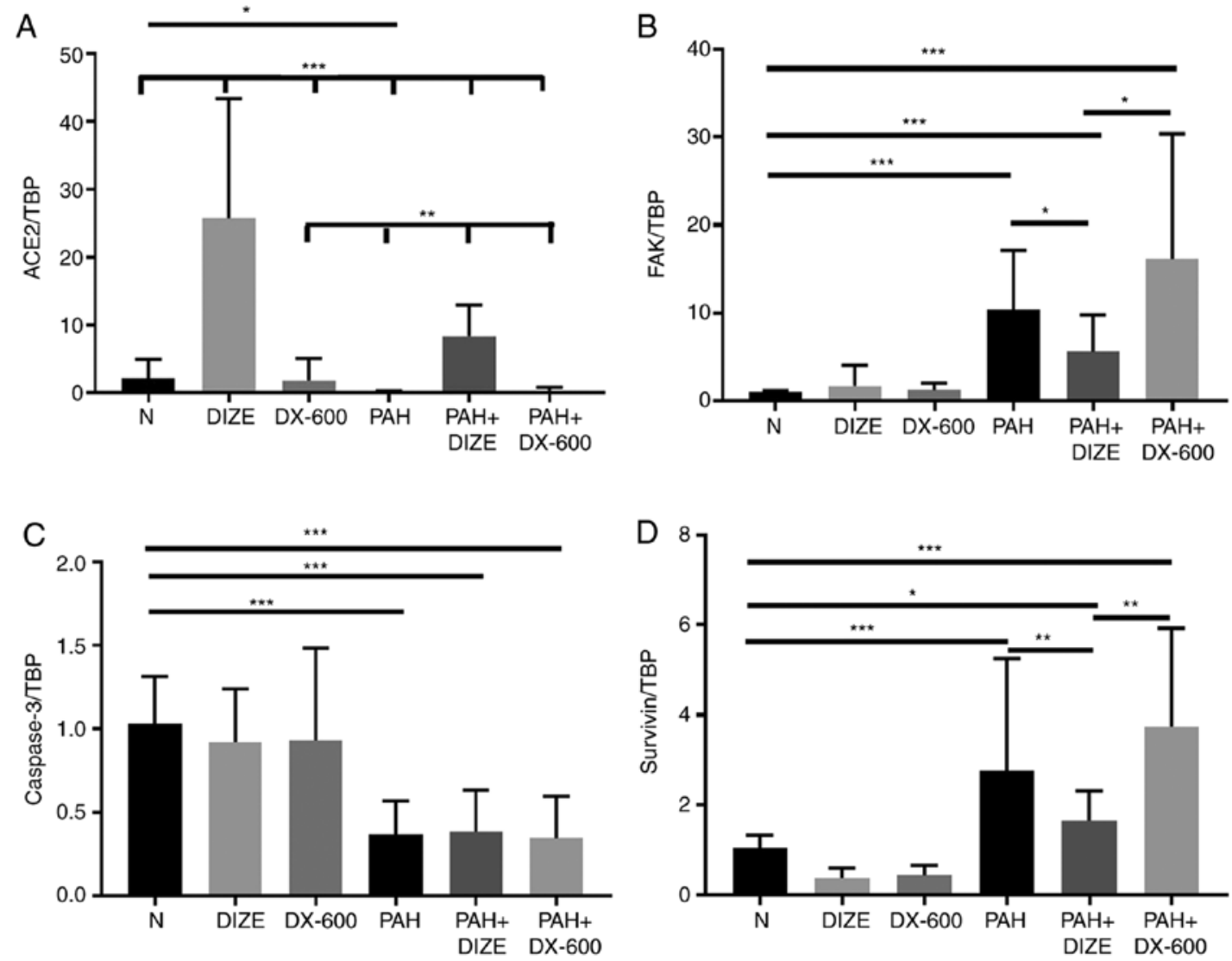

Figure 4. Effect of DIZE on mRNA expression in the rat PAH model. Rats were randomly divided into N, DIZE, DX-600, PAH, PAH + DIZE and PAH + DX-600 groups (n=6/group). The DIZE, PAH + DIZE, DX-600 and PAH + DX-600 groups were injected with DIZE or DX-600 for the first 3 weeks of hypoxia. mRNA expression of (A) ACE2, (B) FAK, (C) caspase-3 and (D) survivin. ${ }^{*} \mathrm{P}<0.05,{ }^{* *} \mathrm{P}<0.01,{ }^{* * *} \mathrm{P}<0.001$. TBP, TATA-binding protein; ACE2, angiotensin-converting enzyme 2; FAK, focal adhesion kinase; N, normoxic; DIZE, diminazene aceturate; PAH, pulmonary artery hypertension.

H\&E staining results indicated that the pulmonary arteries in the $\mathrm{N}$ group had large and thin walls with a regular arrangement of the endothelium and smooth muscle cells (Fig. 2D). The pulmonary arterioles in the PAH group were similar in external diameter, but had decreased internal diameter, increased wall asymmetry, stenosis of the lumen, decreased number of nonmuscular arteries and increased number of muscular arteries compared with the $\mathrm{N}$ group (Fig. 2D). In addition, reduced distal pulmonary artery muscularization and media fraction thickness were observed in the $\mathrm{N}$ group, compared with the PAH group (Fig. 2D). Compared with the $\mathrm{N}$ group, the rats in the PAH group showed significant weight loss, increased RVSP and RVHI and thickened pulmonary arterioles.

Compared with the PAH + DIZE group, the rats in the PAH and PAH + DX-600 groups had significantly reduced weight (Fig. 2B). DIZE caused no significant effect on the RVSP of rats in the normoxia groups (data not shown), but a reduction in RVSP was noted in the PAH + DIZE group compared with the PAH group (Fig. 2A). HE staining and micrograph examination showed that the thickening of pulmonary arterioles was less severe in the PAH + DIZE group compared with in the PAH group, whilst the thickening in the PAH + DX-600 group was more severe (Fig. 2D). These results showed the muscularization of the distal pulmonary artery in the PAH + DIZE group was less than that in the PAH group and the PAH + DX-600 group (Fig. 2D). The media fraction thickness of the distal pulmonary artery was also compared in each group, which found that the proportion of the media fraction in the PAH group and the PAH+DX-600 group was significantly higher than that in the PAH + DIZE group (Fig. 2D). These findings suggested that PAH modeling was successful. Additionally, DIZE caused no significant difference in weight, RVSP, RVHI or pathology between normoxic groups. However, DIZE treatment in rats with PAH led to increased weight, decreased RVSP and RVHI, and thinner pulmonary arterioles compared with PAH alone.

DIZE reduces FAK expression in the PAH rat model. Blood samples were collected, and hemorrhagic serum was separated to observe the effect of DIZE on FAK expression in rats using ELISA (Fig. 3). No significant difference was found in FAK expression between the N and DIZE groups; both groups exhibited reduced levels compared with the DX-600 group. FAK levels in the PAH group were significantly higher compared with that in the $\mathrm{N}$ group and the DIZE group. Furthermore, FAK expression was significantly lower in the $\mathrm{PAH}+$ DIZE group compared with those in the PAH and PAH + DX-600 groups (Fig. 3). These findings suggested that ACE2 could reduce FAK expression in the PAH group, but the effect was not as marked in the normoxic group.

DIZE inhibits the expression of FAK and its downstream proteins in the PAH rat model. The mRNA expression levels of 
A

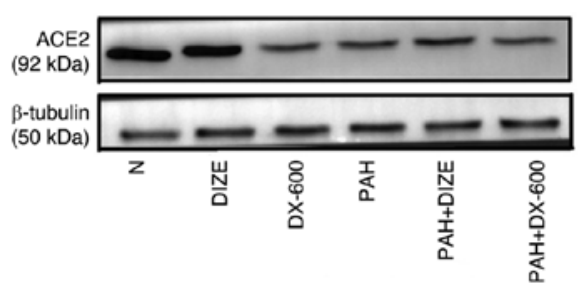

B

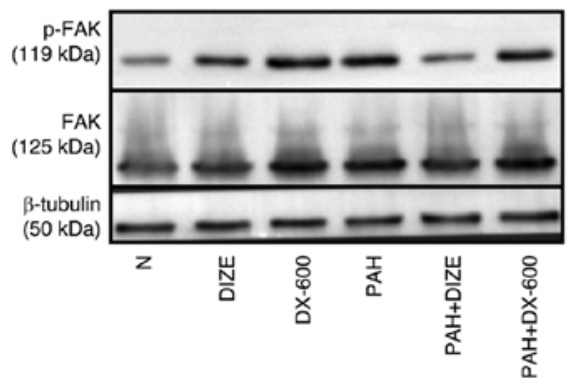

C

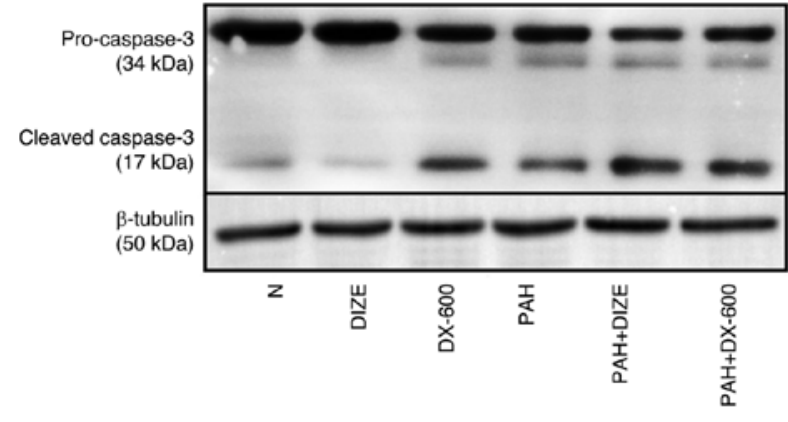

D

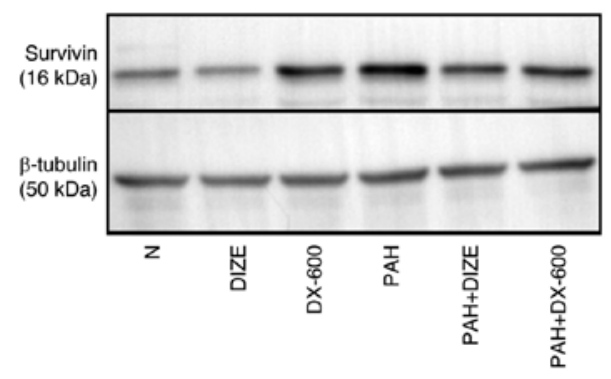

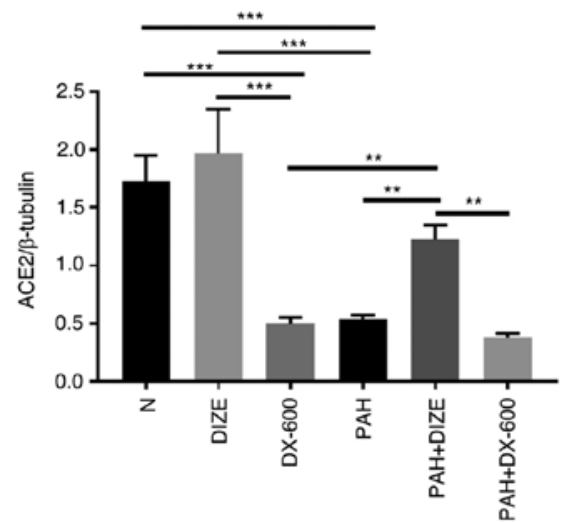
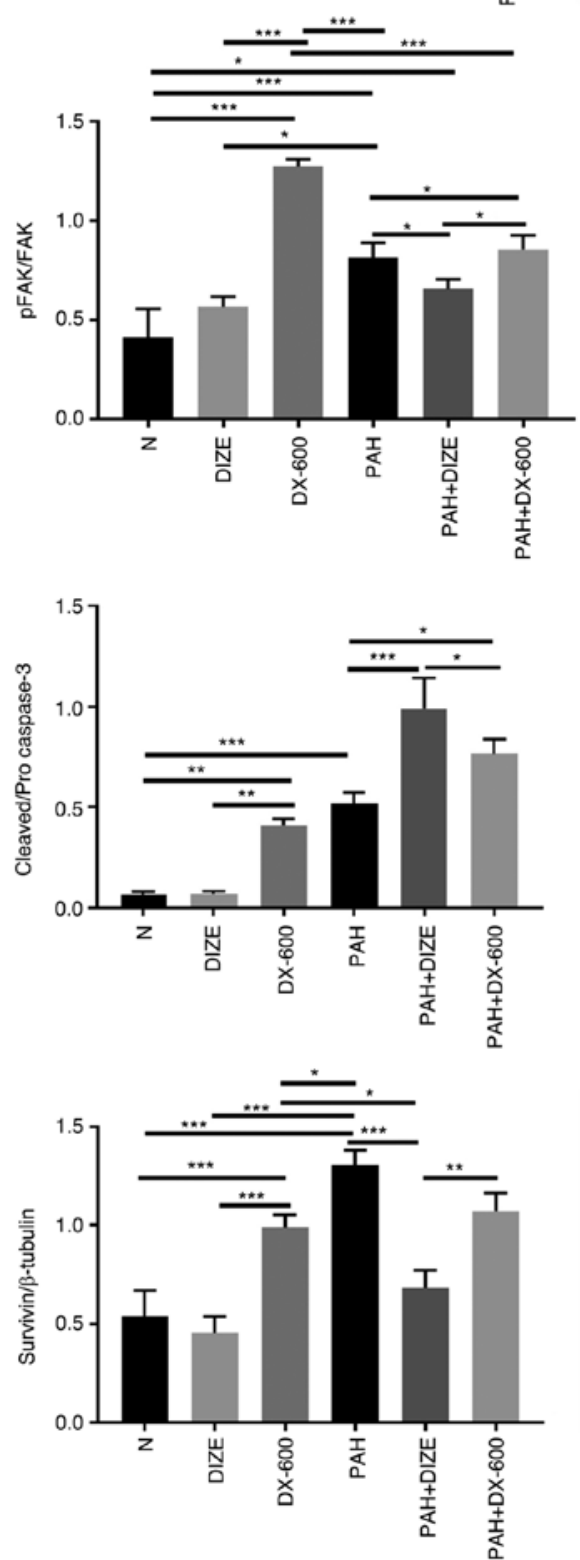

Figure 5. Effect of DIZE on protein expression in the rat PAH model. Rats were randomly divided into N, DIZE, DX-600, PAH, PAH + DIZE and PAH + DX-600 groups (n=6/group). The DIZE, PAH + DIZE, DX-600 and PAH + DX-600 groups were injected with DIZE or DX-600 for the first 3 weeks of hypoxia. Representative western blots and quantification of the expression of (A) ACE2, (B) p-FAK/FAK (C), cleaved caspase-3/pro-caspase-3 and (D) survivin in the rat model. ${ }^{*} \mathrm{P}<0.05,{ }^{* *} \mathrm{P}<0.01,{ }^{* * *} \mathrm{P}<0.001$. ACE2, angiotensin-converting enzyme 2; FAK, focal adhesion kinase; N, normoxic; DIZE, diminazene aceturate; PAH, pulmonary artery hypertension; $\mathrm{p}$, phosphorylated.

ACE2 and caspase-3 decreased, and the mRNA expression levels of FAK and survivin increased, in the PAH group compared with the $\mathrm{N}$ group (Fig. 4A-D). These results indicated that PAH was accompanied by inhibition of ACE2 and activation of FAK. Correspondingly, the addition of DIZE increased the mRNA expression levels of ACE2, and decreased the mRNA expression 

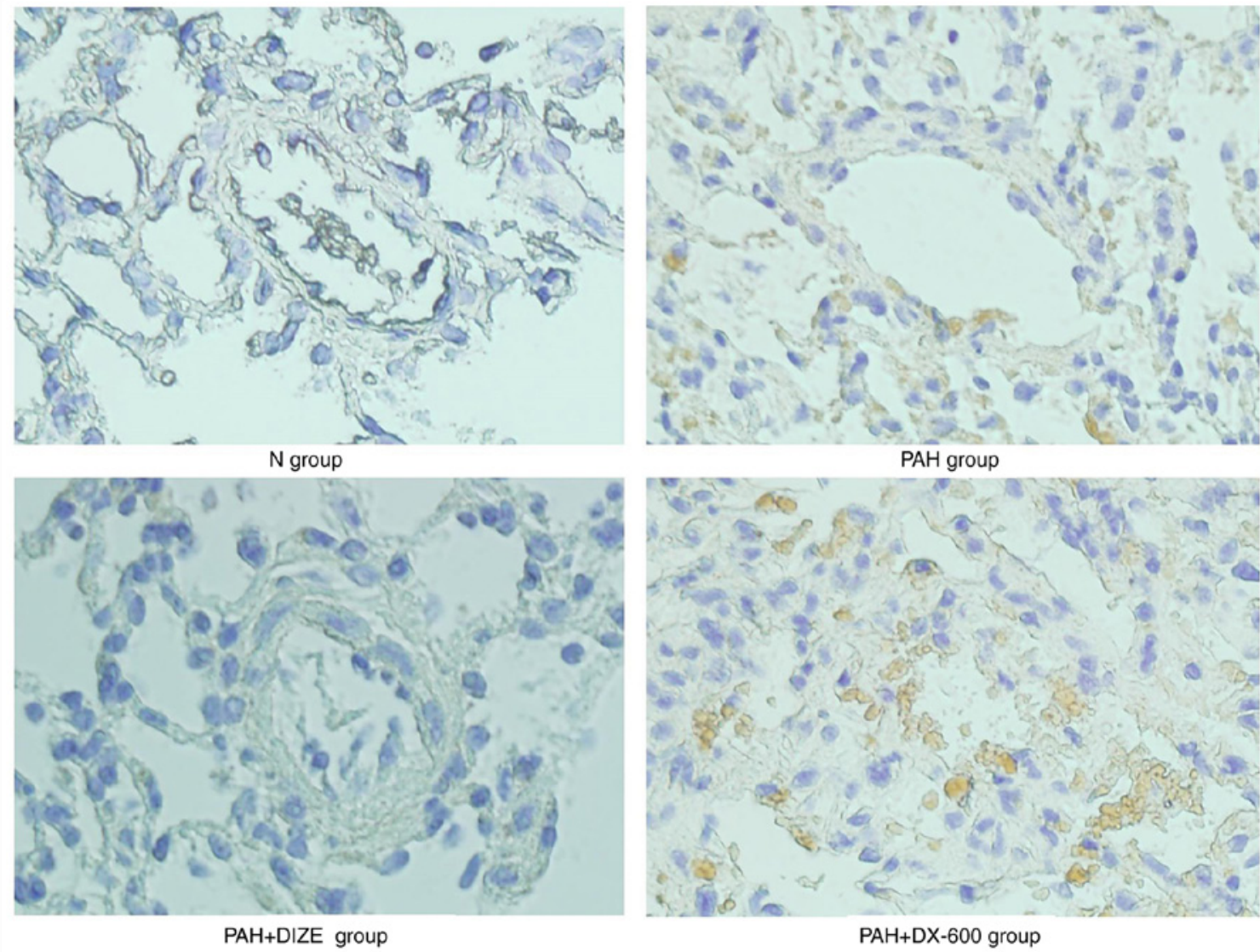

Figure 6. IHC staining of FAK expression. Representative IHC images of FAK expression in the rat model for the N group, the PAH group, the PAH + DIZE group and the PAH + DX-600 group (magnification, x400). FAK staining is shown in brown. IHC, immunohistochemistry; ACE2, angiotensin-converting enzyme 2; FAK, focal adhesion kinase; N, normoxic; DIZE, diminazene aceturate; PAH, pulmonary artery hypertension.

levels of FAK and survivin, in PAH animals compared with the PAH only group. However, significant differences in the mRNA expression of caspase- 3 between the PAH group and the PAH + DIZE group were not observed, nor between the PAH group and the PAH + DX-600 group (Fig. 4A-D).

The protein expression levels of the aforementioned factors were observed using western blot analysis to verify whether they were affected by the addition of DIZE. The results showed that the trend was similar to that of mRNA results. Compared with the PAH group, the expression of ACE2 in the $\mathrm{N}$ group and the DIZE group was significantly higher. However, there was no significant difference in ACE2 expression between the DX-600 group and the PAH group. Compared with the $\mathrm{PAH}+\mathrm{DIZE}$ group, the expression of ACE2 in the PAH group and the PAH + DX-600 group was significantly decreased (Fig. 5A). The p-FAK/FAK ratio in the DX-600 group was significantly increased compared with the $\mathrm{N}$ group and the DIZE group, whilst this ratio in the PAH + DIZE group was significantly reduced compared with the PAH group and the PAH + DX-600 group (Fig. 5B). Compared with the $\mathrm{N}$ group, the cleaved caspase-3/pro-caspase-3 ratio of the three PAH groups increased, whilst the ratio in the PAH + DIZE group was significantly increased compared with the other two PAH groups (Fig. 5C). The expression of survivin in PAH group was significantly higher than that in $\mathrm{N}$ group, DIZE group, DX-600 group and PAH + DIZE group, but there was no significant difference between the PAH group and
PAH+DX-600 group. The expression of survivin in the PAH + DIZE group was significantly lower than that in the PAH group and the PAH + DX-600 group (Fig. 5D). Therefore, it was concluded that DIZE promoted the expression of ACE2 and cleaved caspase-3/pro-caspase-3, whilst inhibiting the levels of p-FAK/FAK and survivin in rats with PAH (Fig. 5A-D).

IHC staining was performed to further observe FAK expression around the pulmonary arterioles. Analysis of the three groups that underwent normoxia were not significantly different under the microscope (data not shown). FAK expression was notably increased in the PAH group compared with the $\mathrm{N}$ group. Additionally, FAK expression was markedly lower in the PAH + DIZE group compared with in the PAH group, while its expression level was markedly higher in the PAH + DX-600 group compared with in the aforementioned three groups (Fig. 6).

These findings suggested that PAH was accompanied by inhibition of ACE2 and activation of FAK. However, ACE2 activation in PAH inhibited FAK expression.

DIZE increases apoptosis in PAH rats. TUNEL staining was performed to assess the effect of DIZE on rats with PAH. The apoptosis level appeared reduced in the PAH group compared with the $\mathrm{N}$ group. Conversely, the apoptosis level was higher in the PAH + DIZE group compared with the PAH group and the PAH + DX-600 group (Fig. 7A and B). These findings suggested that DIZE promoted apoptosis around the pulmonary arterioles. 
A

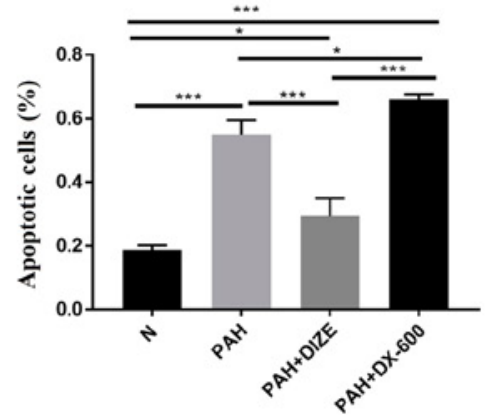

DAPI

FITC
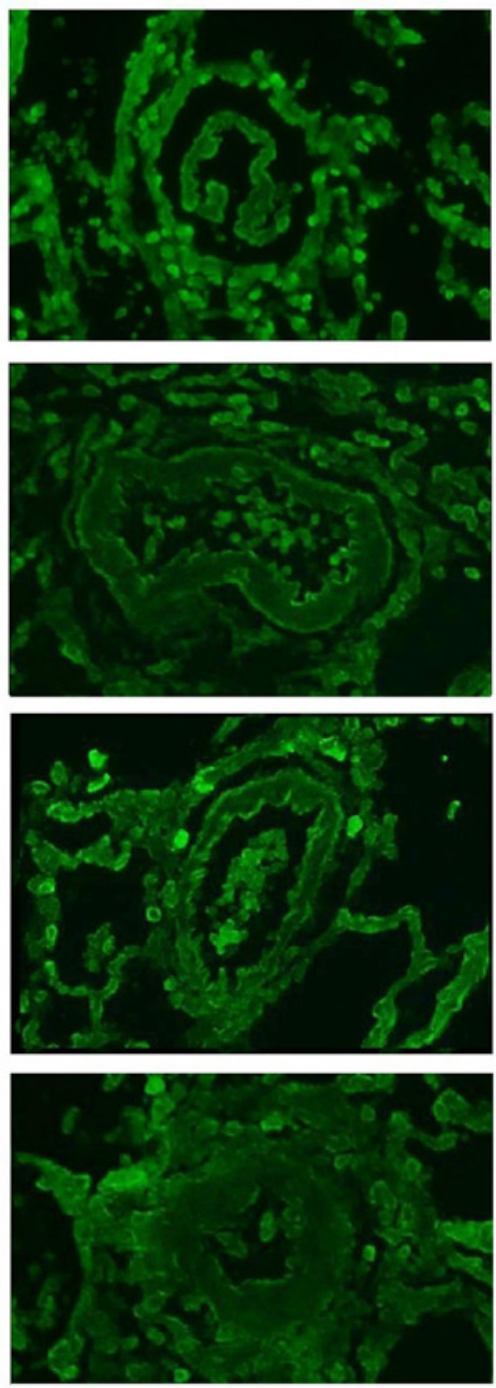

Merged
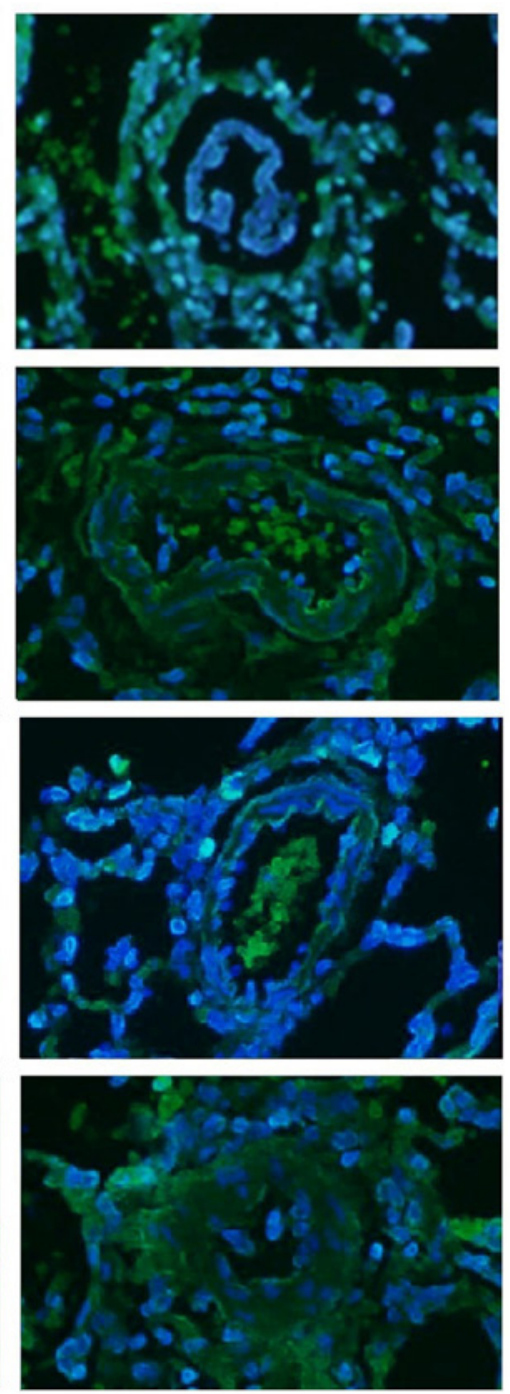

Figure 7. Apoptosis in the PAH model. (A) Quantification of TUNEL-positive cells in each group, and (B) representative images of TUNEL-positive cells in the $\mathrm{N}$ group, the PAH group, the PAH + DIZE group and the PAH + DX-600 group (magnification, $\mathrm{x} 400$ ). ${ }^{*} \mathrm{P}<0.05,{ }^{* * *} \mathrm{P}<0.001$. N, normoxic; DIZE, diminazene aceturate; $\mathrm{PAH}$, pulmonary arterial hypertension.

\section{Discussion}

In the present study, it was identified that ACE2 was downregulated during PAH development in a PAH rat model of MCT treatment combined with continuous hypoxia, and that ACE2 upregulation helped promote apoptosis and led to relief from PAH. In addition, ACE2 activation inhibited p-FAK/FAK and survivin expression in a PAH rat model, and promoted cleaved caspase-3/pro-caspase-3 expression, thus promoting apoptosis around the pulmonary arterioles and reducing the circumference of the arterioles. However, compared with the PAH + DIZE group, the expression of p-FAK/FAK and survivin in the PAH + DX-600 group was increased, whilst the expression of cleaved caspase-3/pro-caspase-3 was decreased, which was also accompanied by the thickening of pulmonary arterioles and the decrease of cell apoptosis around pulmonary arterioles. Taken together, these findings suggested that ACE2 promoted apoptosis in rats with PAH 
by inhibiting the FAK/survivin pathway and promoting caspase-3 expression.

The present study showed that rats with PAH showed a decrease in ACE2 expression compared with controls, which was consistent with previous reports $(34,41)$. Research into ACE2 has examined its role in a number of conditions, including the treatment of myocardial infarction, myocardial fibrosis (42), heart failure (43) and liver fibrosis (44). ACE2 expression is also reportedly reduced under hypoxic conditions (45). ACE2 activation has been shown to attenuate the devastating effects of Ang II in the cardiovascular system by affecting macrophage function (46) and increasing Ang (1-7) generation (47). ACE2, a novel ACE homolog, binds to the Mas receptor and metabolizes ang I into inactive Ang (1-9), as well as Ang II into Ang (1-7). Ang (1-7) can also be generated directly from ang (1-9) via cleavage by ACE (42). It has been reported that Ang (1-7) activation promotes nitric oxide release, increases superoxide dismutase- 2 expression, reduces the production of inflammatory factors and reduces plasma oxidative stress in right heart hypertrophy and cardiac fibrosis $(48,49)$.

Perivascular pulmonary arterial and systemic inflammation is reported to contribute to the initiation and maintenance of pulmonary vascular hypertension, while oxidative stress and inflammation, in an interactive manner, play a major role in the development of PVR (50). This is consistent with the experimental results of the present study, which showed that ACE2 activation improved $\mathrm{PAH}$ and reduced right ventricular hypertrophy. $\mathrm{PAH}$, whether idiopathic or related to underlying diseases, such as human immunodeficiency virus infection, results from complex vessel remodeling involving both PASMC proliferation and inflammation (51). Early application of ACE2 can also reduce PVR and promote apoptosis, but the specific mechanism is unknown (41). The proliferation of PASMCs is the pathological basis of PVR, which, in turn, is a major factor in the continuous progression and irreversibility of PAH (52). To investigate the association between ACE2 and PASMC apoptosis, the expression of apoptosis-related proteins was further examined in the present study. The results suggested that ACE2 may promote apoptosis via caspase-3 activation and FAK inhibition. Previous studies demonstrated that ACE2 improved acute lung injury (ALI) by inhibiting apoptosis $(53,54)$. In ALI, neutrophils release proinflammatory and pro-apoptotic cytokines to harm neighboring cells and weaken the alveolar-capillary barrier; ACE2 reduces the severity of ALI by hydrolyzing Ang II and the ALI-induced apoptosis of pulmonary endothelial cells (54). However, in proliferative lung diseases such as PAH, ACE2 can promote apoptosis by hydrolyzing Ang II (55). It is currently believed that the inhibition of ACE2 activity causes the imbalance between Ang II and Ang (1-7). As a bridge between Ang II and Ang (1-7), inhibited ACE2 will cause an increase in Ang II and a decrease in Ang (1-7) (56). Although research on Ang II is still in its infancy, increased Ang II levels has been shown to be an important risk factor in breast cancer, COVID-19 and PAH $(56,57)$. The therapeutic effect of ACE2 varies with the diseases caused by Ang II. Therefore, it is hypothesized that Ang II-mediated pulmonary vascular inflammation promotes the proliferation of PASMCs in PAH and that ACE2 inhibits it. In addition, ACE2 activation has been indicated to increase caspase-3 expression through the ACE2-Ang (1-7)-Mas axis in cultured human umbilical vein endothelial cells (58), in line with the experimental results of the present study.

To understand how ACE2 activates caspase- 3 in PAH, the present study focused on signaling pathways associated with tumor progression, since there are similarities with PAH in terms of aberrant cell proliferation (59). As Ang II has been widely shown to promote FAK activation during the development of liver fibrosis and kidney disease, it is hypothesized that this association may also exist in the development of PAH and the hydrolysis of Ang II by ACE2 may inhibit the activation of FAK $(21,23,24)$. This hypothesis is consistent with the experimental results of the present study, which indicated that ACE2 inhibited FAK expression and phosphorylation and expression of its downstream factors. The results of the present study also indicated that FAK inhibition increased caspase-3 expression. Pro-caspase-3 is predominant in normal cells, and caspase-3 can be cleaved after activation of apoptosis signals to promote cell apoptosis (60). This is consistent with the experimental results in the PAH model groups, where there was an increase in the ratio of cleaved caspase-3/pro-caspase-3, with the highest level seen in the PAH + DIZE group. Increased levels of FAK expression are common in patients with liver cancer and cirrhosis and may not be improved after liver transplantation, increasing patient mortality (61). A study reported that after FAK inhibition, caspase-3 expression increased and the p38 pathway was mediated to inhibit compensatory cell proliferation in liver cancer (62). Although the sequence of changes in the expression of FAK and caspase-3 cannot be clarified, the decrease in FAK expression and the increase in caspase- 3 expression were simultaneously observed, which was previusly found in myocardial ischemia (63), triple-negative breast cancer (64) and human non-small cell lung cancer (65).

In conclusion, ACE2 activation may reduce the progression of PAH through the inhibition of FAK expression. Further experiments will be conducted to explore this pathway in cultured PASMCs, to confirm that ACE2 inhibits FAK and reduces PAH by inhibiting PASMC proliferation. Further mechanistic studies may be of great benefit for the development of clinical guidance and improved patient outcomes.

\section{Acknowledgements}

Not applicable.

\section{Funding}

This study was supported by grants from the Wuxi Medical Innovation Team (grant no. CXTD001) and the Major Natural Science Research Project of Jiangsu Higher Education Institutions (grant no. 19KJA560004).

\section{Availability of data and materials}

The datasets used and/or analyzed during the current study are available from the corresponding author on reasonable request.

\section{Authors' contributions}

RW, ZW, JX and SG contributed to the study design, data acquisition, analysis, statistical analysis and manuscript preparation. 
RW and JW contributed to analysis and interpretation of data, and revised the manuscript critically for important intellectual content. All authors read and approved the final manuscript. RW, ZW, JX and SG confirm the authenticity of all the raw data.

\section{Ethics approval and consent to participate}

The present study was approved by the Institutional Animal Care and Use Committee of Wuxi People's Hospital Affiliated to Nanjing Medical University (Wuxi, China).

\section{Patient consent for publication}

Not applicable.

\section{Competing interests}

The authors declare that they have no competing interests.

\section{References}

1. Wang L, Zhu X, Zhao LP, Wang M, Liu X, Chen Y, Chen J and $\mathrm{Xu} \mathrm{W}$ : Effect of beraprost on pulmonary hypertension due to left ventricular systolic dysfunction. Medicine (Baltimore) 98 e14965, 2019.

2. Mammoto T, Muyleart M, Konduri GG and Mammoto A: Twist1 in hypoxia-induced pulmonary hypertension through transforming growth factor- $\beta$-smad signaling. Am J Respir Cell Mol Biol 58: 194-207, 2018.

3. Agrawal V, Byrd BF III and Brittain EL: Echocardiographic evaluation of diastolic function in the setting of pulmonary hypertension. Pulmonary Circulation 9: 2045894019826043, 2019.

4. Bartelds B, van Loon RLE, Mohaupt S, Wijnberg H Dickinson MG, Boersma B, Takens J, van Albada M and Berger RMF: Mast cell inhibition improves pulmonary vascular remodeling in pulmonary hypertension. Chest 141: 651-660, 2012.

5. Sayed BA, Christy A, Quirion MR and Brown MA: The master switch: The role of mast cells in autoimmunity and tolerance. Annu Rev Immunol 26: 705-739, 2008.

6. Tkaczyk C, Frandji P, Botros HG, Poncet P, Lapeyre J, Peronet R, David B and Mécheri S: Mouse bone marrow-derived mast cells and mast cell lines constitutively produce $B$ cell growth and differentiation activities. J Immunol 157: 1720-1728, 1996

7. Breitling S, Hui Z, Zabini D, Hu Y, Hoffmann J, Goldenberg NM, Tabuchi A, Buelow R, Dos Santos C and Kuebler WM: The mast cell-B cell axis in lung vascular remodeling and pulmonary hypertension. Am J Physiol Lung Cell Mol Physiol 312: L710-L721, 2017.

8. Mao M, Yu X, Ge X, Gu R, Li Q, Song S, Zheng X, Shen T, Li X, Fu Y, et al: Acetylated cyclophilin A is a major mediator in hypoxia-induced autophagy and pulmonary vascular angiogenesis. J Hypertens 35: 798-809, 2017.

9. Rui C, Jiang M, Bo L, Zhong W, Wang Z, Yuan W and Yan J: The role of autophagy in pulmonary hypertension: A double-edge sword. Apoptosis 23: 459-469, 2018.

10. Overgaard J: Hypoxic radiosensitization: Adored and ignored. J Clin Oncol 25: 4066-4074, 2007.

11. Barnes H, Brown Z, Burns A and Williams T: Phosphodiesterase 5 inhibitors for pulmonary hypertension. Cochrane Database Syst Rev 31: CD012621, 2019.

12. West CM, Wearing OH, Rhem RG and Scott GR: Pulmonary hypertension is attenuated and ventilation-perfusion matching is maintained during chronic hypoxia in deer mice native to high altitude. Am J Physiol Regul Integr Comp Physiol 320: R800-R811, 2021.

13. Pullamsetti SS, Kojonazarov B, Storn S, Gall H, Salazar Y, Wolf J, Weigert A, El-Nikhely N, Ghofrani HA, Krombach GA, et al: Lung cancer-associated pulmonary hypertension: Role of microenvironmental inflammation based on tumor cell-immune cell cross-talk. Sci Transl Med 9: eaai9048, 2017.
14. Li XN, Xu JJ, Wu JB, Ji L, Yuan CH and Wang ZP: Curcumin exerts protective effect on PC12 cells against lidocaine-induced cytotoxicity by suppressing the formation of NLRP3 inflammasome. Eur Rev Med Pharmacol Sci 24: 7092-7100, 2020.

15. Zhao XK, Yu L, Cheng ML, Che P, Lu YY, Zhang Q, Mu M, Li H, Zhu LL, Zhu JJ, et al: Focal adhesion kinase regulates hepatic stellate cell activation and liver fibrosis. Sci Rep 7: 4032-4044, 2017.

16. Paulin R, Meloche J, Courboulin A, Lambert C, Haromy A, Courchesne A, Bonnet P, Provencher S, Michelakis ED and Bonnet S: Targeting cell motility in pulmonary arterial hypertension. Eur Respir J 43: 531-544, 2013.

17. Lin C, Li X, Luo Q, Yang H, Li L, Zhou Q, Li Y, Tang H and Wu L: RELM- $\beta$ promotes human pulmonary artery smooth muscle cell proliferation via FAK-stimulated surviving. Exp Cell Res 351: 43-50, 2017

18. Ferreira-Pinto MJ, Silva AF, Nogueira-Ferreira R, Padrao AI, Moreira-Goncalves D, Carneiro F, Costa R, Ribeiro L, Leite-Moreira AF and Henriques-Coelho T: Survivin role in pulmonary arterial hypertension. Eur Heart J 34 (Suppl 1): P302, 2013.

19. Fan Z, Liu B, Zhang S, Liu H, Li Y, Wang D, Liu Y, Li J, Wang N, Liu Y and Zhang B: YM155, a selective survivin inhibitor, reverses chronic hypoxic pulmonary hypertension in rats via upregulating voltage-gated potassium channels. Clin Exp Hypertens 37: 381-387, 2015.

20. Mitra SK and Schlaepfer DD: Integrin-regulated FAK-Src signaling in normal and cancer cells. Curr Opin Cell Biol 18: 516-523, 2006

21. Clarke NE, Fisher MJ, Porter KE, Lambert DW and Turner AJ: Angiotensin converting enzyme (ACE) and ACE2 bind integrins and ACE2 regulates integrin signalling. PLoS One 7: e34747, 2012.

22. Chen Y, Cao J, Zhao Q, Luo H, Wang Y and Dai W: Silencing MR-1 attenuates atherosclerosis in $\mathrm{ApoE}^{-/-}$mice induced by angiotensin II through FAK-Akt-mTOR-NF-kappaB signaling pathway. Korean J Physiol Pharmacol 22: 127-134, 2018.

23. Xu XP, He HL, Hu SL, Han JB, Huang LL, Xu JY, Xie JF, Liu AR, Yang Y and Qiu HB: Ang II-AT2R increases mesenchymal stem cell migration by signaling through the FAK and RhoA/Cdc42 pathways in vitro. Stem Cell Res Ther 8: 164, 2017.

24. Hall G, Wu G and Winn M: 112 Ang II Induces FAK activation and podocyte migration via a TRPC6-dependent mechanism. Am J Kidney Dis 57: B44, 2011.

25. Seguin LR, Villarreal RS and Ciuffo GM: $\mathrm{AT}_{2}$ receptors recruit c-Src, SHP-1 and FAK upon activation by Ang II in PND15 rat hindbrain. Neurochem Int 60: 199-207, 2012.

26. Watanabe F, Miyazaki T, Takeuchi T, Fukaya M, Nomura T, Noguchi S, Mori H, Sakimura K, Watanabe M and Mishina M: Effects of FAK ablation on cerebellar foliation, Bergmann glia positioning and climbing fiber territory on Purkinje cells. Eur J Neurosci 27: 836-854, 2010.

27. George AJ, Thomas WG and Hannan RD: The renin-angiotensin system and cancer: Old dog, new tricks. Nat Rev Cancer 10: 745-759, 2010.

28. Jiang Y, Zhou Y, Peng G, Liu N, Tian H, Pan D, Liu L, Yang X, Li C, Li W, et al: Topotecan prevents hypoxia-induced pulmonary arterial hypertension and inhibits hypoxia-inducible factor-1a and TRPC channels. Int J Biochem Cell Biol 104: 161-170, 2018.

29. Imanishi $M$, Tomita S, Ishizawa K, Kihira Y, Ueno $M$, Izawa-Ishizawa Y, Ikeda Y, Yamano N, Tsuchiya K and Tamaki T: Smooth muscle cell-specific Hif-1 $\alpha$ deficiency suppresses angiotensin II-induced vascular remodelling in mice. Cardiovasc Res 102: 460-468, 2014

30. Kittana N: Angiotensin-converting enzyme 2-Angiotensin 1-7/1-9 system: Novel promising targets for heart failure treatment. Fundam Clin Pharmacol 32: 14-25, 2018.

31. Zhou X, Zhang P, Liang T, Chen Y, Liu D and Yu H: Relationship between circulating levels of angiotensin-converting enzyme 2-angiotensin-(1-7)-MAS axis and coronary heart disease. Heart Vessels 35: 153-161, 2020.

32. de Man FS, Tu L, Handoko ML, Rain S, Ruiter G, François C, Schalij I, Dorfmüller P, Simonneau G, Fadel E, et al: Dysregulated renin-angiotensin-aldosterone system contributes to pulmonary arterial hypertension. Am J Respir Crit Care Med 186: 780-789, 2012.

33. National Research Council (US) Committee for the Update of the Guide for the Care and Use of Laboratory Animals: Guide for the care and use of laboratory animals. 8th edition. The National Academies Press, Washington, DC, 2011. 
34. Rigatto K, Casali KR, Shenoy V, Katovich MJ and Raizada MK Diminazene aceturate improves autonomic modulation in pulmonary hypertension Eur J Pharmacol 713: 89-93, 2013.

35. Yanhong Z, Lina $M$ and Shanshan C: Mechanism of small intestine injury in non-steroidal anti-inflammatory drugs rats mediated by RAS-p38MAPK signal pathway. In: Proceedings of the 4th International Conference on Digestive Diseases of the World Federation of Chinese Medicine Societies, Zhengzhou, pp308-311, 2013.

36. Fraga-Silva RA, Sorg BS, Wankhede M, Dedeugd C, Jun JY, Baker MB, Li Y, Castellano RK, Katovich MJ, Raizada MK and Ferreira AJ: ACE2 activation promotes antithrombotic activity. Mol Med 16: 210-215, 2010.

37. Li Y, Wang Y, Li Y, Qian Z, Zhu L and Yang D: Osthole attenuates pulmonary arterial hypertension in monocrotaline-treated rats. Mol Med Rep 16: 2823-2829, 2017.

38. Kwon MY, Hwang N, Park YJ, Perrella MA and Chung SW: NOD2 deficiency exacerbates hypoxia-induced pulmonary hypertension and enhances pulmonary vascular smooth muscle cell proliferation. Oncotarget 9: 12671-12681, 2018.

39. Livak KJ and Schmittgen TD: Analysis of relative gene expression data using real-time quantitative PCR and the 2(-Delta Delta $\mathrm{C}(\mathrm{T})$ ) method. Methods 25: 402-408, 2001.

40. Jones R, Jacobson M and Steudel W: Alpha-smooth-muscle actin and microvascular precursor smooth-muscle cells in pulmonary hypertension. Am J Respir Cell Mol Biol 20: 582-594, 1999.

41. Hemnes AR, Rathinasabapathy A, Austin EA, Brittain EL, Carrier EJ, Chen X, Fessel JP, Fike CD, Fong P, Fortune N, et al: A potential therapeutic role for angiotensin-converting enzyme 2 in human pulmonary arterial hypertension. Eur Respir J 51 1702638,2018

42. Wang J, He W, Guo L, Zhang Y, Li H, Han S and Shen D: The ACE2-Ang (1-7)-Mas receptor axis attenuates cardiac remodeling and fibrosis in post-myocardial infarction. Mol Med Rep 16: 1973-1981, 2017.

43. Patel VB, Lezutekong JN, Chen X and Oudit GY: Recombinant human ACE2 and the angiotensin 1-7 axis as potential new therapies for heart failure. Can J Cardiol 33: 943-946, 2017.

44. Hu Q, Hu Z, Chen Q, Huang Y, Mao Z, Xu F and Zhou X: BML-111 equilibrated ACE-AngII-AT1R and ACE2-Ang-(1-7)-Mas axis to protect hepatic fibrosis in rats. Prostaglandins Other Lipid Mediat 131: 75-82, 2017.

45. Shenoy V, Qi Y, Katovich MJ and Raizada MK: ACE2, a promising therapeutic target for pulmonary hypertension. Curr Opin Pharmacol 11: 150-155, 2011

46. Hammer A, Yang G, Friedrich J, Kovacs A, Lee DH, Grave K, Jörg S, Alenina N, Grosch J, Winkler J, et al: Role of the receptor Mas in macrophage-mediated inflammation in vivo. Proc Nat Acad Sci USA 113: 14109-14114, 2016.

47. Yang G, Chu PL, Rump LC, Le TH and Stegbauer J: ACE2 and the homolog collectrin in the modulation of nitric oxide and oxidative stress in blood pressure homeostasis and vascular injury. Antioxid Redox Signal 26: 645-659, 2017.

48. Zhang ZZ, Cheng YW, Jin HY, Chang Q, Shang QH, Xu YL, Chen LX, Xu R, Song B and Zhong JC: The sirtuin 6 prevents angiotensin II-mediated myocardial fibrosis and injury by targeting AMPK-ACE2 signaling. Oncotarget 8: 72302-72314, 2017.

49. Zhang J, Dong J, Martin M, He M, Gongol B, Marin TL, Chen L, Shi X, Yin Y, Shang F, et al: AMP-activated protein kinase phosphorylation of angiotensin-converting enzyme 2 in endothelium mitigates pulmonary hypertension. Am J Respir Crit Care Med 198: 509-520, 2018.

50. Sun XQ, Abbate A and Bogaard HJ: Role of cardiac inflammation in right ventricular failure. Cardiovasc Res 113: 1441-1452, 2017.
51. Amsellem V, Lipskaia L, Abid S, Poupel L, Houssaini A, Quarck R, Marcos E, Mouraret N, Parpaleix A, Bobe R, et al: CCR5 as a treatment target in pulmonary arterial hypertension. Circulation 130: 880-891, 2014

52. Bello-Klein A, Mancardi D, Araujo AS, Schenkel PC, Turck P and de Lima Seolin BG: Role of redox homeostasis and inflammation in the pathogenesis of pulmonary arterial hypertension. Curr Med Chem 25: 1340-1351, 2018.

53. Fang Y, Gao F, Hao J and Liu Z: microRNA-1246 mediates lipopolysaccharide-induced pulmonary endothelial cell apoptosis and acute lung injury by targeting angiotensin-converting enzyme 2. Am J Transi Res 9: 1287-1296, 2017

54. Wang L, Li Y, Qin H, Xing D, Su J and Hu Z: Crosstalk between ACE2 and PLGF regulates vascular permeability during acute lung injury. Am J Transl Res 8: 1246-1252, 2016.

55. Li G, Liu Y, Zhu Y, Liu A, Xu Y, Li X, Li Z, Su J and Sun L: ACE2 activation confers endothelial protection and attenuates neointimal lesions in prevention of severe pulmonary arterial hypertension in rats. Lung 191: 327-336, 2013.

56. Bujak-Gizycka B, Madej J, Bystrowska B, Toton-Zuranska J, Kus K, Kolton-Wroz M, Jawien J and Olszanecki R: Angiotensin 1-7 formation in breast tissue is attenuated in breast cancer-a study on the metabolism of angiotensinogen in breast cancer cell lines. J Physiol Pharmacol 70: 503-514, 2019.

57. Amirfakhryan $\mathrm{H}$ and Safari F: Outbreak of SARS-CoV2: Pathogenesis of infection and cardiovascular involvement. Hellenic J Cardiol 62: 13-23, 2021.

58. Zhang X, Pan Y and Jin HM: Aldosterone induced endothelial cell apoptosis via modulation of ACE2-Ang (1-7)-Mas receptor axis. J Shanghai Jiao Univ (Med Sci) 33: 6-11, 2013.

59. Gao ML, Chen L, Li YF, Xue XC, Chen L, Wang LN, Shah W and Kong Y: Synergistic increase of oxidative stress and tumor markers in PAH-exposed workers. Asian Pac J Cancer Prev 15: 7105-7112, 2014.

60. Putt KS, Chen GW, Pearson JM, Sandhorst JS, Hoagland MS, Kwon JT, Hwang SK, Jin H, Churchwell MI, Cho MH, et al: Small-molecule activation of procaspase- 3 to caspase- 3 as a personalized anticancer strategy. Nat Chem Biol 2: 543-550, 2006.

61. Fujii T, Koshikawa K, Nomoto S, Okochi O, Kaneko T, Inoue S, Yatabe Y, Takeda S and Nakao A: Focal adhesion kinase is overexpressed in hepatocellular carcinoma and can be served as an independent prognostic factor. J Hepatol 41: 104-111, 2004.

62. Shang N, Bank T, Ding X, Breslin P, Li J, Shi B and Qiu W: Caspase-3 suppresses diethylnitrosamine-induced hepatocyte death, compensatory proliferation and hepatocarcinogenesis through inhibiting p38 activation. Cell Death Dis 9: 558, 2018.

63. Kanazawa H, Imoto K, Okada $M$ and Yamawaki H: Canstatin inhibits hypoxia-induced apoptosis through activation of integrin/focal adhesion kinase/Akt signaling pathway in $\mathrm{H} 9 \mathrm{c} 2$ cardiomyoblasts. PLoS One 12: e0173051, 2017.

64. Oh E, Sung D, Cho Y, Kim JY, Lee N, Kim YJ, Cho TM and Seo JH: Abstract 5463: Disulfiram suppresses metastasis via induction of anoikis and calpain activation in triple-negative breast cancer. Cancer Res 77 (Suppl 13): S5463, 2017.

65. Cai F, Chen M, Zha D, Zhang P, Zhang X, Cao N, Wang J, He Y, Fan X, Zhang W, et al: Curcumol potentiates celecoxib-induced growth inhibition and apoptosis in human non-small cell lung cancer. Oncotarget 8: 115526-115545, 2017.

This work is licensed under a Creative Commons Attribution-NonCommercial-NoDerivatives 4.0 International (CC BY-NC-ND 4.0) License. 